\title{
Identification of KIF4A as a pan-cancer diagnostic and prognostic biomarker via bioinformatics analysis and validation in osteosarcoma cell lines
}

\author{
Jiankang Pan ${ }^{1}$, Xiaohua Lei ${ }^{\text {Corresp., } 2}$, Xinzhan Mao ${ }^{\text {Corresp. } 1}$ \\ ${ }^{1}$ Department of Orthopedics, the Second Xiangya Hospital, Central South University, Changsha, Hunan, China \\ 2 Department of Hepato-Biliary-Pancreatic Surgery, the First Affiliated Hospital of University of South China, Hengyang, Hunan, China \\ Corresponding Authors: Xiaohua Lei, Xinzhan Mao \\ Email address: leixiaohua@csu.edu.cn, xinzhan.mao@csu.edu.cn
}

Background: Cancer is a disease of abnormal cell proliferation caused by abnormal expression of cancer-related genes. However, it is still difficult to distinguish benign and malignant lesions in many cases. KIF4A has been reported to be associated with a variety of cancer lesions. We aimed to explore whether KIF4A could be used as a biomarker of pan-cancer diagnostic. Methods: We identified twenty-eight cell cycle-related genes that were overexpressed in no less than ten types of cancer. We determined KIF4A mRNA and protein expression in osteosarcoma (OS) cells. Furthermore, to determine the effect of KIF4A in OS, we silenced KIF4A in OS cells and detected cell viability, colony formation, invasion, migration, apoptosis and cell cycle parameters. Results: KIF4A exhibited upregulated expression in eleven types of cancer. Cell cycle-related genes are extensively overexpressed in various types of cancers. KIF4A overexpression can serve as a diagnostic and prognostic marker in various cancers. Silencing KIF4A inhibited the viability, colony formation, invasion and migration and induced apoptosis and cell cycle arrest of OS cells. Our findings revealed that high expression of KIF4A could serve as a diagnostic and prognostic marker in OS cancers. Conclusion: KIF4A could serve as a pan-cancer diagnostic and prognostic marker. KIF4A could be used as a novel therapeutic target for OS. 
3 Jiankang $\operatorname{Pan}^{1}$, Xiaohua Lei²*, and Xinzhan Mao ${ }^{1 *}$

$4{ }^{1}$ Department of Orthopedics, the Second Xiangya Hospital, Central South University, Changsha, $5 \quad$ Hunan 410011, China

$6{ }^{2}$ Department of Hepato-Biliary-Pancreatic Surgery, the First Affiliated Hospital of University of 7 South China, Hengyang, Hunan 421001, China.

$9 *$ Correspondence:

10 Xiaohua Lei, Department of Hepato-Biliary-Pancreatic Surgery, the First Affiliated Hospital of 11 University of South China, Hengyang, Hunan 421001, China.

12 Email: leixiaohua@csu.edu.cn;

13 Xinzhan Mao, Department of Orthopedics, The Second Xiangya Hospital, Central South 14 University, Changsha, Hunan 410011, China

15 Email: xinzhan.mao@csu.edu.cn. 


\section{Abstract}

24 Background: Cancer is a disease of abnormal cell proliferation caused by abnormal expression of 25 cancer-related genes. However, it is still difficult to distinguish benign and malignant lesions in many cases. KIF4A has been reported to be associated with a variety of cancer lesions. We aimed to explore whether KIF4A could be used as a biomarker of pan-cancer diagnostic.

Methods: We identified twenty-eight cell cycle-related genes that were overexpressed in no less than ten types of cancer. We determined KIF4A mRNA and protein expression in osteosarcoma (OS) cells. Furthermore, to determine the effect of KIF4A in OS, we silenced KIF4A in OS cells and detected cell viability, colony formation, invasion, migration, apoptosis and cell cycle parameters.

Results: KIF4A exhibited upregulated expression in eleven types of cancer. Cell cycle-related genes are extensively overexpressed in various types of cancers. KIF4A overexpression can serve as a diagnostic and prognostic marker in various cancers. Silencing KIF4A inhibited the viability, colony formation, invasion and migration and induced apoptosis and cell cycle arrest of OS cells.

37 Our findings revealed that high expression of KIF4A could serve as a diagnostic and prognostic marker in OS cancers.

39 Conclusion: KIF4A could serve as a pan-cancer diagnostic and prognostic marker. KIF4A could 40 be used as a novel therapeutic target for OS.

41 Keywords: bioinformatics analysis, chromosome instability biomarker, KIF4A, OS 
43 Osteosarcoma (Osteosarcoma, OS) is the most common malignant bone tumor in the world 44 (accounting for nearly $60 \%$ of bone malignant tumors), which seriously affects the daily life of 45 patients ${ }^{1}$. Essentially, cancer is a disease of abnormal cell proliferation caused by accumulated 46 genomic mutations ${ }^{2}$. Previous studies in molecular medicine have divided cancers into 47 increasingly specific molecular subtypes according to their specific genomic status or 48 transcriptome pattern, which has greatly improved the prognosis of many cancer types ${ }^{3-5}$. 49 However, it is still difficult to distinguish benign and malignant lesions in many cases. There is an 50 urgent need for effective treatment. Therefore, it is necessary to identify different cancers 51 according to the current trend of developing more precise drugs.

52 Transcriptome analysis to identify differential gene expression between tumor and paired normal 53 tissues can help to reveal the key process of cell proliferation in cancer. RNA-seq data from the 54 Cancer Genome Atlas (TCGA) dataset could systematically analyze the expression profiles of 55 bidirectional genes and gene pairs in cancer ${ }^{6}$. We plan to screen RNA-seq data covering dozens of 56 cancers and matched normal tissues from TCGA. We will further use bioinformatics to analyze 57 whether KIF4A is involved in chromosome segregation and whether it is abnormally expressed in 58 various types of cancer.

59 The KIF4A gene encodes the chromokinesin protein KIF4A, an Adenosine triphosphate (ATP) 60 dependent molecular motor that promotes mitotic chromosome condensation and segregation ${ }^{7}$. 61 KIF4A can also directly bind to chromatin and participate in DNA damage repair by associating 62 with BRCA2 ${ }^{8,9}$. Many studies have noted the presence of upregulated expression of KIF4A in 63 various cancer tissues and its positive correlation with poor prognosis ${ }^{10-13}$.

64 However, the role of KIF4A in OS remains unknown. We studied the role of KIF4A in OS cells. 65 Our results indicated that KIF4A could be a predictive factor and therapeutic target in OS. 


\section{The Cancer Genome Atlas (TCGA) dataset}

68 Data acquisition and analysis were conducted using $\mathrm{R}$ software (version 3.5.1 or above), unless

69 otherwise mentioned. RNA-seq and clinical data were downloaded using the TCGA Biolinks

$70 \mathrm{R} /$ Bioconductor package (version 2.10.5) ${ }^{14,15}$. Generally, we used TCGA Biolinks to download

71 all available samples with Illumina HiSeq RNASeqV2 data from 33 cancer types.

\section{Data analysis, gene network analysis and pathway enrichment analysis}

73 The fragments per kilobase of transcript per million fragments mapped (FPKM) parameter is the

74 most commonly used normalization method for analyzing RNA transcript reads. The upper

75 quantile normalized FPKM (FPKM-UQ ) method have used the upper quantile gene count instead

76 of the total gene count for normalization, which is considered to have superior sensitivity in the

77 identification of gene differential expression ${ }^{16,17}$. In this study, FPKM-UQ RNA-seq data were

78 downloaded and prepared using the GDC query, GDC download, and GDC prepare functions. All

79 analysis codes used are freely available at https://github.com/hutaobo/prognosis.

\section{Cell Culture and Transfection}

81 The normal osteoblast cell line hFOB1.19 and the human OS cell lines MG63, U2OS and HOS

82 were purchased from the Cell Bank of the Chinese Academy of Sciences and cultured in $5 \% \mathrm{CO}_{2}$

83 at $37^{\circ} \mathrm{C}$ in DMEM (Sigma) containing 10\% FBS (Gibco), $100 \mathrm{U} / \mathrm{ml}$ penicillin and $100 \mathrm{pg} / \mathrm{ml}$

84 streptomycin. The cells were evaluated in the logarithmic growth phase. A siRNA against

85 KIF4A (siKIF4A) and EX-A3631-Lv105 (oe-KIF4A, GeneCopoeia, Inc.) were purchased, and

86 the transfection was performed using Lipofectamine 2000 (Invitrogen). 


\section{Cell Counting Kit-8 (CCK-8)}

88 To assess cell viability, cells were seeded in a $96-$ well plate at a density of $5 \times 10^{3}$ cells per well. At

89 the indicated times (24, 48 and $72 \mathrm{~h}), 10 \mu \mathrm{lCCK}-8$ solution (Dojindo) was added to each well, and

90 the plates were incubated at $37^{\circ} \mathrm{C}$ for $2 \mathrm{~h}$. The proliferation of cells was determined with a CCK-

918 assay kit. The absorbance was measured at $450 \mathrm{~nm}$.

\section{Wound healing assay}

93 The cells were seeded in 6-well plates and incubated to nearly $100 \%$ confluence. The cell

94 monolayer was scratched with a $10 \mu$ plastic pipette tip. The wells were washed with phosphate-

95 buffered saline (PBS), FBS was added to the well, and the area of scratch closure was used to

96 estimate the migratory ability with an inverted phase microscope. The percentage of wound closure

97 was calculated as a ratio of the wound area at $24 \mathrm{~h}$ to that at $0 \mathrm{~h}$ and $48 \mathrm{~h}$.

\section{Cell colony formation}

99 The indicated cells $(200$ cells $/ 2 \mathrm{ml})$ were plated into 6-well plates and incubated for two weeks.

100 The colonies were fixed with methanol and stained with $1 \%$ crystal violet. The absorbance was

101 measured at $550 \mathrm{~nm}$.

\section{Flow Cytometry Analysis}

103 Cell cycle parameters were detected by propidium iodide (PI) staining. Briefly, $48 \mathrm{~h}$ after 104 transfection, cells were collected and fixed overnight with $90 \%$ cold ethanol at $20^{\circ} \mathrm{C}$. The next 105 day, the cells were incubated at RT for 5 min. The cells were washed with PBS twice and then 106 cultured with $1 \mathrm{ml}$ PI staining solution $(50 \mu \mathrm{g} / \mathrm{ml} ; 1 \mathrm{mg} / \mathrm{ml}$ RNase A, and $0.1 \%$ Triton X-100 in 
107 PBS) in the dark for $30 \mathrm{~min}$. Cell cycle proportions were detected by flow cytometry (FACS

108 Calibur).

109 Cell apoptosis was detected by using Annexin V-FITC/PI double staining. Briefly, after the

110 transfected cells were collected and washed, they were incubated with $500 \mu l$ binding buffer, $5 \mu l$

111 Annexin V-FITC (BD) and $5 \mu$ l propidium iodide (PI). The apoptotic rate was determined by using

112 flow cytometry.

\section{Western blotting}

114 Proteins were separated using a 10\% SDS-PAGE gel and then transferred to PVDF membranes.

115 After blocking in nonfat milk, the immunoblots were incubated with primary antibodies against

116 the following molecules: KIF4A (1:1000, ab122227, Abcam), Bax (1:2000, ab32503, Abcam),

117 Bcl-2 (1:1000, 12789-1-AP, Proteintech), cleaved-caspase 3 (1:500, ab32042, Abcam), Wnt3a

118 (1:1000, ab28472, Abcam), $\beta$-catenin (1:6000, 51067-2-AP, Proteintech) and p- $\beta$-catenin (1:500,

119 PA5-36827, proteintech) were purchased. Anti- $\beta$-actin antibodies (1:5000, 66009-1-Ig,

120 Proteintech) were used as an internal control. Protein bands were visualized using an enhanced

121 chemiluminescence (ECL) machine (Advansta).

\section{Transwell assay}

123 Transwell assays were conducted to detect cell invasion. Crystalline violet was dissolved in 95\%

124 ethanol, mixed with ammonium oxalate solution, and stood for 48 hours. A total of $1 \times 10^{6}$ cells

125 were added to the upper chambers and cultured in $200 \mathrm{ml}$ serum-free DMEM. After incubation for

$12648 \mathrm{~h}$ at $37^{\circ} \mathrm{C}$, the upper surface of the membrane was wiped with a cotton tip, and the cells on the 
127 lower membrane were fixed with $4 \%$ polyformaldehyde and stained with $0.1 \%$ crystal violet for

$12830 \mathrm{~min}$. The absorbance was measured at $550 \mathrm{~nm}$.

\section{Real-time quantitative reverse transcription PCR (qRT-PCR) analysis}

130 The transcription level was determined by qRT-PCR. Briefly, total RNA of the cells was

131 dissociated with an RNA extraction kit. RNA was reverse-transcribed into cDNA with a reverse

132 transcription kit (ComWin Biotech). Quantification of gene expression was conducted using the

$1332-\Delta \Delta \mathrm{CT}$ method, and the results were normalized to $\beta$-actin mRNA levels. The sequences of the

134 primers were as follows: KIF4A: F-TGTTGGATGTGGGCCTTAGC, R-

135 GTGACTTAGCACCCTTCTGGA; $\quad \beta$-actin: $\quad$ F-ACCCTGAAGTACCCCATCGAG, $\quad$ R-

136 AGCACAGCCTGGATAGCAAC.

137 Statistical analysis

138 All bioinformatic analyses were conducted using R software. The SPSS22.0 software program was

139 used for the statistical analysis. The t-test and one-way analysis of variance (ANOVA) were used

140 for comparisons between two groups, and comparisons among multiple groups were made using

141 two-way ANOVA. P $<0.05$ was considered statistically significant.

\section{Results}

143 Cell cycle-related genes are extensively overexpressed in various types of cancers

144 The expression of 57,035 genes in 12 types of cancer and their paired normal tissues from TCGA 145 were analyzed. The 12 analyzed types of cancers were breast invasive carcinoma (BRCA) ${ }^{18}$, 
146 kidney renal clear cell carcinoma (KIRC) ${ }^{19}$, lung adenocarcinoma (LUAD) ${ }^{20}$, stomach

147 adenocarcinoma $(\mathrm{STAD})^{21}$, colon adenocarcinoma $(\mathrm{COAD})^{22}$, kidney renal papillary cell

148 carcinoma (KIRP) ${ }^{23}$, lung squamous cell carcinoma (LUSC) ${ }^{24}$, thyroid carcinoma (THCA) ${ }^{25}$, head

149 and neck squamous cell carcinoma $(\mathrm{HNSC})^{26}$, liver hepatocellular carcinoma (LIHC) ${ }^{27}$, prostate

150 adenocarcinoma (PRAD) ${ }^{28}$, and uterine corpus endometrial carcinoma (UCEC) ${ }^{29}$. The sample

151 number for each cancer type is listed in Table 1.

152 For statistical analysis, only those genes reaching genome-wide significance were included and

153 defined as differentially expressed genes (DEGs) ( $\mathrm{p}$ value less than $\left.5 \times 10^{-8}\right)^{30}$. Approximately

154 three-quarters of the genes did not show elevated expression in any cancer type. Thus, only $9 \%$ of

155 all the analyzed genes $(n=5343)$ showed elevated expression in more than one type of cancer.

156 Among them, 28 genes were found to be overexpressed in no less than 10 types of cancer (Table

157 2). In gastric adenocarcinoma and thyroid cancer, only 6 and 13 of 28 pan-cancer DEGs are

158 overexpressed. In the other 10 cancer types, at least 20 DEGs are overexpressed. This difference

159 was not caused by sample size, as thyroid carcinoma had the third largest sample size. Therefore,

160 this finding indicates the existence of an intrinsic difference in stomach adenocarcinoma and

161 thyroid carcinoma compared with other cancer types. The Gene Ontology (GO) molecular pathway

162 analysis showed that the 28 pan-cancer DEGs were enriched in 116 biological processes, most of

163 which were cell cycle-related processes (Table S1). This is no surprise, since cancer is essentially

164 a disease of uncontrolled cell proliferation. However, only 28 DEGs of 1263 genes involved in the

165 cell cycle have been extensively altered in different types of cancer. This suggested that these

166 genes may be the key to cancer cell cycle regulation. The 28 selected DEGs also had strong

167 protein-protein interactions, as plotted using STRING (Figure 1A).

168 KIF4A overexpression can serve as a diagnostic and prognostic marker in various cancers 
169 Among the pan-cancer DEGs, KIF4A showed elevated expression in eleven types of cancer

170 (Figure 1B-M). KIF4A was also found to be upregulated in multiple cancer types. Elevated

171 expression of the KIF4A protein was also verified in five types of cancer using

172 immunohistochemistry data from the Human Protein Atlas (HPA; Figure S1).

173 High expression of the KIF4A gene was significantly correlated with poor prognosis in four kinds

174 of cancer, KIRC, KIRP, LUAD, and LIHC, as shown by Kaplan-Meier survival analysis (Figure $1751 \mathrm{~N}-\mathrm{Q})$.

\section{Expression of KIF4A in OS cell lines}

177 To further validate the bioinformatics analysis results, the expression of KIF4A in OS cell lines 178 was detected. The above analysis results found that KIF4A is highly expressed in osteosarcoma. 179 We determined the mRNA and protein expression of KIF4A in three OS cell lines (MG63, U2OS 180 and HOS) and normal osteoblast cells using RT-PCR and Western blotting (Figure 2). The results 181 showed that the level of mRNA and protein of KIF4A in osteosarcoma cell lines were significantly 182 higher than those of normal osteoblasts hFOB1.19. The results of TCGA data analysis were 183 consistent with the results of cell experiment.

185 Effect of silencing KIF4A on the viability, colony formation, invasion and migration of OS 186 cells

187 Among the three OS cell lines, KIF4A expression was highest in MG63 and U2OS cells; therefore, 188 these two lines were chosen for subsequent assays. The silencing plasmid and overexpression 189 plasmid was transfected into MG63 and U20S cells respectivel. The results showed that the 190 transfection was successful (Figure 3A-D). The CCK-8 assay revealed that decreased KIF4A 191 expression markedly suppressed the viability of MG63 and U2OS cells. Overexpression of KIF4A 
192 enhanced cell viability (Figure 3E and F). Colony formation experiments showed that after

193 knocking out KIF4A, the cloning ability of MG63 and U2OS cells was greatly reduced. After

194 overexpression of KIF4A, the clonality of cells was promoted (Figure 3G-I), which indicated that

195 KIF4A increased the stemness of OS cells. Transwell assays revealed that the silencing of KIF4A

196 strikingly decreased the invasion ability of MG63 and U2OS cells (Figure 4A and B). However,

197 the cell invasion ability of the oe-KIF4A group was significantly increased. The date of wound 198 healing assay showed that the migration ability of MG63 and U2OS cells was significantly 199 decreased after KIF4A knockdown. After KIF4A was up-regulated, the cell migration ability 200 increased significantly (Figure 4C-F). In short, KIF4A could affect the activity of MG63 and 201 U2OS cells.

202

203 Effect of KIF4A silencing on the apoptosis and cell cycle of OS cells

204 The above results indicate that KIF4A could affect the activity of MG63 and U20S cells. We 205 further investigated whether apoptosis would be affected. Flow cytometry results showed that 206 KIF4A silencing could induce apoptosis, leading to cell cycle arrest in G1 phase. KIF4A

207 208 209

210

211

212

213

\section{Discussion}


215 Kinesin superfamily(KIF) proteins play a key role in cellular functions, such as mitosis and 216 intracellular transport of organelles and vesicles, and there are 14 recognized kinesin families

217 (kinesin 1-14A/B $)^{31}$. Upregulated expression of KIF proteins leads to premature separation of 218 chromosomes, which can cause progression of cancer ${ }^{32,}$ 33. The KIF4A gene encodes the 219 chromokinesin protein KIF4A, an ATP-dependent molecular motor that promotes mitotic 220 chromosome condensation and segregation ${ }^{7}$. KIF4A can also directly bind to chromatin and 221 participate in DNA damage repair by associating with BRCA2 ${ }^{8,9}$. Many studies have shown that 222 the expression of KIF4A in liver cancer, cervical cancer and oral cancer tissues is up-regulated, 223 and is positively correlated with poor prognosis ${ }^{10-13}$. KIF4A overexpression might promote lung 224 cancer resistance to cisplatin, while in breast cancer cells, its overexpression promotes cell 225 apoptosis during treatment with doxorubicin ${ }^{34}$.

226 Our bioinformatics analysis results showed that overexpression of KIF4A played a role in mitosis 227 and could become a potential new diagnostic and prognostic marker for various cancers. The 228 observed pan-cancer upregulation of KIF4A is probably an indicator of the increased mitotic rate 229 in cancer cells. High KIF4A expression was correlated with poor overall survival of OS patients. 230 In vitro experiments showed that silencing KIF4A could inhibit OS cell viability, colony 231 formation, migration and invasion, and induce apoptosis and cell cycle arrest.

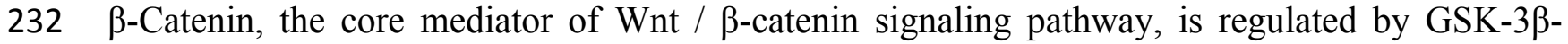
233 promoted phosphorylation and ubiquitin / proteasome pathway degradation. $\beta$-catenin mutation 234 could lead to the abnormal activation of Wnt target gene, leading to the occurrence of cancer ${ }^{35}$. 235 The Wnt/ $\beta$-catenin signaling pathway plays an important role in chromosomal instability ${ }^{36}$. 236 Various studies have proven that the Wnt/ $\beta$-catenin signaling pathway is implicated in the 
237 pathogenesis of cancers, especially OS ${ }^{37-40}$. Our results indicated that KIF4A modulates the

$238 \mathrm{Wnt} / \beta$-catenin pathway in OS cells.

239 In conclusion, KIF4A could be used as a biomarker and prognostic indicator for pan-cancer

240 diagnostic. KIF4A could regulate Wnt/ $\beta$-catenin signaling as a new target for OS therapy.

241 Supplementary materials: Figure S1: Validation of KIF4A protein expression in various cancers

242 and paired normal tissues using the Human Protein Atlas (HPA) database. Samples were classified

243 into high or low expression groups according to the mean expression level of KIF4A; the groups

244 comprised the highest and lowest thirds of patients, respectively. Table S1: Functional enrichment

245 of the 28 pan-cancer DEGs via STRING analysis.

\section{Funding}

247 This work is supported by the following grants: Hunan Provincial Health and Family Planning 248 Commission Research Project, Grant No. 20180343. Health Commission of Hunan Province 249 Research Project Grant No.20200284.

250

251

252

253

254

255

256

257

258

259

260

\section{References}

1. Gianferante, D. M.; Mirabello, L., Germline and somatic genetics of osteosarcoma connecting aetiology, biology and therapy. Nat Rev Endocrinol 2017, 13 (8), 480-491.

2. Hu, T.; Kumar, Y.; Shazia, I.; Duan, S. J.; Li, Y.; Chen, L.; Chen, J. F.; Yin, R.; Kwong, A.; Leung, G. K.; Mat, W. K.; Wu, Z.; Long, X.; Chan, C. H.; Chen, S.; Lee, P.; Ng, S. K.; Ho, T. Y. C.; Yang, J.; Ding, X.; Tsang, S. Y.; Zhou, X.; Zhang, D. H.; Zhou, E. X.; Xu, L.; Poon, W. S.; Wang, H. Y.; Xue, H., Forward and reverse mutations in stages of cancer development. Hum Genomics 2018, 12 (1), 40.

3. Yang, C.; Wang, Y. T.; Zheng, C. H., A Random Walk Based Cluster Ensemble Approach for Data Integration and Cancer Subtyping. Genes (Basel) 2019, 10 (1). 
261 4. Hu, T.; Chen, S.; Ullah, A.; Xue, H., AluScanCNV2: An R package for copy number variation 262 calling and cancer risk prediction with next-generation sequencing data. Genes Dis 2019, 6 (1), 263 43-46.

264 5. Knight, D. A.; Grainge, C. L.; Stick, S. M.; Kicic, A.; Schuliga, M., Epithelial Mesenchymal 265 Transition in Respiratory Disease: Fact or Fiction. Chest 2020, 157 (6), 1591-1596.

266 6. Tu, J.; Li, X., Characterization of bidirectional gene pairs in The Cancer Genome Atlas (TCGA) 267 dataset. PeerJ 2019, 7, e7107.

268 7. Mazumdar, M.; Sundareshan, S.; Misteli, T., Human chromokinesin KIF4A functions in 269 chromosome condensation and segregation. J Cell Biol 2004, 166 (5), 613-20.

270 8. Wu, G.; Chen, P. L., Structural requirements of chromokinesin Kif4A for its proper function in 271 mitosis. Biochem Biophys Res Commun 2008, 372 (3), 454-8.

272 9. Wu, G.; Zhou, L.; Khidr, L.; Guo, X. E.; Kim, W.; Lee, Y. M.; Krasieva, T.; Chen, P. L., 273 A novel role of the chromokinesin Kif4A in DNA damage response. Cell Cycle 2008, 7 (13), 201327420.

275 10. Hou, G.; Dong, C.; Dong, Z.; Liu, G.; Xu, H.; Chen, L.; Liu, L.; Wang, H.; Zhou, W., 276 Upregulate KIF4A Enhances Proliferation, Invasion of Hepatocellular Carcinoma and Indicates 277 poor prognosis Across Human Cancer Types. Sci Rep 2017, 7 (1), 4148.

278 11. Narayan, G.; Bourdon, V.; Chaganti, S.; Arias-Pulido, H.; Nandula, S. V.; Rao, P. H.; 279 Gissmann, L.; Dürst, M.; Schneider, A.; Pothuri, B.; Mansukhani, M.; Basso, K.; Chaganti, 280 R. S.; Murty, V. V., Gene dosage alterations revealed by cDNA microarray analysis in cervical 281 cancer: identification of candidate amplified and overexpressed genes. Genes Chromosomes 282 Cancer 2007, 46 (4), 373-84.

283 12. Taniwaki, M.; Takano, A.; Ishikawa, N.; Yasui, W.; Inai, K.; Nishimura, H.; Tsuchiya, 284 E.; Kohno, N.; Nakamura, Y.; Daigo, Y., Activation of KIF4A as a prognostic biomarker and 285 therapeutic target for lung cancer. Clin Cancer Res 2007, 13 (22 Pt 1), 6624-31.

286 13. Minakawa, Y.; Kasamatsu, A.; Koike, H.; Higo, M.; Nakashima, D.; Kouzu, Y.; 287 Sakamoto, Y.; Ogawara, K.; Shiiba, M.; Tanzawa, H.; Uzawa, K., Kinesin family member 4A: 288 a potential predictor for progression of human oral cancer. PLoS One 2013, 8 (12), e85951.

289 14. Colaprico, A.; Silva, T. C.; Olsen, C.; Garofano, L.; Cava, C.; Garolini, D.; Sabedot, 290 T.S.; Malta, T. M.; Pagnotta, S. M.; Castiglioni, I.; Ceccarelli, M.; Bontempi, G.; Noushmehr, 291 H., TCGAbiolinks: an R/Bioconductor package for integrative analysis of TCGA data. Nucleic Acids 292 Res 2016, 44 (8), e71.

293 15. Le, N. Q. K., XGBoost Improves Classification of MGMT Promoter Methylation Status in IDH1 294 Wildtype Glioblastoma. J Pers Med 2020, 10 (3), 128.

295 16. Hsu, J. B.-K., Radiomic Immunophenotyping of GSEA-Assessed Immunophenotypes of 296 Glioblastoma and Its Implications for Prognosis: A Feasibility Study. Cancers (Basel) 2020, 12 (10), 2973039.

298 17. Bullard, J. H., Evaluation of statistical methods for normalization and differential expression 299 in mRNA-Seq experiments. BMC Bioinformatics 2010, 11 (94). 
300 18. Comprehensive molecular portraits of human breast tumours. Nature 2012, 490 (7418), 6130170.

302 19. Comprehensive molecular characterization of clear cell renal cell carcinoma. Nature 2013, 303499 (7456), 43-9.

304 20. Comprehensive molecular profiling of lung adenocarcinoma. Nature 2014, 511 (7511), 54330550.

306 21. Comprehensive molecular characterization of gastric adenocarcinoma. Nature 2014, 513 307 (7517), 202-9.

308 22. Comprehensive molecular characterization of human colon and rectal cancer. Nature 2012, 309487 (7407), 330-7.

310 23. Linehan, W. M.; Spellman, P. T.; Ricketts, C. J.; Creighton, C. J.; Fei, S. S.; Davis, C.; 311 Wheeler, D. A.; Murray, B. A.; Schmidt, L.; Vocke, C. D.; Peto, M.; Al Mamun, A. A.; 312 Shinbrot, E.; Sethi, A.; Brooks, S.; Rathmell, W. K.; Brooks, A. N.; Hoadley, K. A.; 313 Robertson, A. G.; Brooks, D.; Bowlby, R.; Sadeghi, S.; $\quad$ Shen, H.; Weisenberger, D. J.; 314 Bootwalla, M.; Baylin, S. B.; Laird, P. W.; Cherniack, A. D.; Saksena, G.; Haake, S.; Li, J.; 315 Liang, H.; Lu, Y.; Mills, G. B.; Akbani, R.; Leiserson, M. D.; Raphael, B. J.; Anur, P.; 316 Bottaro, D.; Albiges, L.; Barnabas, N.; Choueiri, T. K.; Czerniak, B.; Godwin, A. K.; Hakimi, 317 A. A.; Ho, T. H.; Hsieh, J.; Ittmann, M.; Kim, W. Y.; Krishnan, B.; Merino, M. J.; Mills 318 Shaw, K. R.; Reuter, V. E.; Reznik, E.; Shelley, C. S.; Shuch, B.; Signoretti, S.; Srinivasan, 319 R.; Tamboli, P.; Thomas, G.; Tickoo, S.; Burnett, K.; Crain, D.; Gardner, J.; Lau, K.; 320 Mallery, D.; $\quad$ Morris, S.; Paulauskis, J. D.; Penny, R. J.; $\quad$ Shelton, C.; Shelton, W. T.; 321 Sherman, M.; Thompson, E.; Yena, P.; Avedon, M. T.; Bowen, J.; Gastier-Foster, J. M.; 322 Gerken, M.; Leraas, K. M.; Lichtenberg, T. M.; Ramirez, N. C.; Santos, T.; Wise, L.; 323 Zmuda, E.; Demchok, J. A.; Felau, I.; Hutter, C. M.; Sheth, M.; Sofia, H. J.; Tarnuzzer, 324 R.; Wang, Z.; Yang, L.; Zenklusen, J. C.; Zhang, J.; Ayala, B.; Baboud, J.; Chudamani, 325 S.; Liu, J.; Lolla, L.; Naresh, R.; Pihl, T.; Sun, Q.; Wan, Y.; Wu, Y.; Ally, A.; 326 Balasundaram, M.; Balu, S.; Beroukhim, R.; Bodenheimer, T.; Buhay, C.; Butterfield, Y. 327 S.; Carlsen, R.; Carter, S. L.; Chao, H.; Chuah, E.; Clarke, A.; Covington, K. R.; Dahdouli, 328 M.; Dewal, N.; Dhalla, N.; Doddapaneni, H. V.; Drummond, J. A.; Gabriel, S. B.; Gibbs, 329 R. A.; Guin, R.; Hale, W.; Hawes, A.; Hayes, D. N.; Holt, R. A.; Hoyle, A. P.; Jefferys, S. 330 R.; Jones, S. J.; Jones, C. D.; Kalra, D.; Kovar, C.; Lewis, L.; Li, J.; Ma, Y.; Marra, M. 331 A.; Mayo, M.; Meng, S.; Meyerson, M.; Mieczkowski, P. A.; Moore, R. A.; Morton, D.; 332 Mose, L. E.; Mungall, A. J.; Muzny, D.; Parker, J. S.; Perou, C. M.; Roach, J.; Schein, J. 333 E.; Schumacher, S. E.; Shi, Y.; Simons, J. V.; Sipahimalani, P.; Skelly, T.; Soloway, M. G.; 334 Sougnez, C.; Tam, A.; Tan, D.; Thiessen, N.; Veluvolu, U.; Wang, M.; Wilkerson, M. D.; 335 Wong, T.; Wu, J.; Xi, L.; Zhou, J.; Bedford, J.; Chen, F.; Fu, Y.; Gerstein, M.; Haussler, 336 D.; Kasaian, K.; Lai, P.; Ling, S.; Radenbaugh, A.; Van Den Berg, D.; Weinstein, J. N.; 337 Zhu, J.; Albert, M.; Alexopoulou, I.; Andersen, J. J.; Auman, J. T.; Bartlett, J.; Bastacky, 338 S.; Bergsten, J.; Blute, M. L.; Boice, L.; Bollag, R. J.; Boyd, J.; Castle, E.; Chen, Y. B.; 
339 Cheville, J. C.; Curley, E.; Davies, B.; DeVolk, A.; Dhir, R.; Dike, L.; Eckman, J.; Engel, 340 J.; Harr, J.; Hrebinko, R.; Huang, M.; Huelsenbeck-Dill, L.; lacocca, M.; Jacobs, B.; 341 Lobis, M.; Maranchie, J. K.; McMeekin, S.; Myers, J.; Nelson, J.; Parfitt, J.; Parwani, A.; 342 Petrelli, N.; Rabeno, B.; Roy, S.; Salner, A. L.; Slaton, J.; Stanton, M.; Thompson, R. H.; 343 Thorne, L.; Tucker, K.; Weinberger, P. M.; Winemiller, C.; Zach, L. A.; Zuna, R., 344 Comprehensive Molecular Characterization of Papillary Renal-Cell Carcinoma. N Engl J Med 2016, $345374(2), 135-45$.

346 24. Comprehensive genomic characterization of squamous cell lung cancers. Nature 2012, 489 347 (7417), 519-25.

348 25. Integrated genomic characterization of papillary thyroid carcinoma. Cell 2014, 159 (3), 67634990.

350 26. Comprehensive genomic characterization of head and neck squamous cell carcinomas. 351 Nature 2015, 517 (7536), 576-82.

352 27. Comprehensive and Integrative Genomic Characterization of Hepatocellular Carcinoma. Cell 353 2017, 169 (7), 1327-1341.e23.

354 28. The Molecular Taxonomy of Primary Prostate Cancer. Cell 2015, 163 (4), 1011-25.

355 29. Cherniack, A. D.; Shen, H.; Walter, V.; Stewart, C.; Murray, B. A.; Bowlby, R.; Hu, 356 X.; Ling, S.; Soslow, R. A.; Broaddus, R. R.; Zuna, R. E.; Robertson, G.; Laird, P. W.; 357 Kucherlapati, R.; Mills, G. B.; Weinstein, J. N.; Zhang, J.; Akbani, R.; Levine, D. A., Integrated 358 Molecular Characterization of Uterine Carcinosarcoma. Cancer Cell 2017, 31 (3), 411-423.

359 30. Panagiotou, O. A.; loannidis, J. P., What should the genome-wide significance threshold be? 360 Empirical replication of borderline genetic associations. Int J Epidemiol 2012, 41 (1), 273-86.

361 31. Jungwirth; Yu; Moustafa; Rapp; Warta; Jungk; Sahm; Dettling; Zweckberger; 362 Lamszus; Senft; Loehr; Keßler; Ketter; Westphal; Debus; von, D.; Simon; Unterberg; 363 Abdollahi; Herold, M., Identification of KIF11 As a Novel Target in Meningioma. Cancers 2019, 11 364 (4).

365 32. Manning, C. S.; Hooper, S.; Sahai, E. A., Intravital imaging of SRF and Notch signalling 366 identifies a key role for EZH2 in invasive melanoma cells. Oncogene 2015, 34 (33), 4320-32.

367 33. Kato, T.; Wada, H.; Patel, P.; Hu, H. P.; Lee, D.; Ujiie, H.; Hirohashi, K.; Nakajima, 368 T.; Sato, M.; Kaji, M.; Kaga, K.; Matsui, Y.; Tsao, M. S.; Yasufuku, K., Overexpression of 369 KIF23 predicts clinical outcome in primary lung cancer patients. Lung Cancer 2016, 92, 53-61.

370 34. Wang, H.; Lu, C.; Li, Q.; Xie, J.; Chen, T.; Tan, Y.; Wu, C.; Jiang, J., The role of Kif4A 371 in doxorubicin-induced apoptosis in breast cancer cells. Mol Cells 2014, 37 (11), 812-8.

372 35. Qi, Y.-B.; Yang, W., Wnt/ $\beta$-catenin signaling modulates piperine-mediated antitumor effects 373 on human osteosarcoma cells. Mol Med Rep 2020, 21 (5), 2202-2208.

374 36. Hadjihannas, M. V.; Behrens, J., CIN By WNT: growth pathways, mitotic control and 375 chromosomal instability in cancer. Cell Cycle 2006, 5 (18), 2077-81. 
376 37. Li, W.; Meng, Z.; Zou, T.; Wang, G.; Su, Y.; Yao, S.; Sun, X., MiR-374a Activates Wnt/ $\beta$ -

377 Catenin Signaling to Promote Osteosarcoma Cell Migration by Targeting WIF-1. Pathol Oncol Res

378 2020, 26 (1), 533-539.

379 38. Zhao, A.; Zhang, Z.; Zhou, Y.; Li, X.; Li, X.; Ma, B.; Zhang, Q., $\beta$-Elemonic acid inhibits

380 the growth of human Osteosarcoma through endoplasmic reticulum (ER) stress-mediated

381 PERK/elF2 $\alpha /$ ATF4/CHOP activation and Wnt/ $\beta$-catenin signal suppression. Phytomedicine 2020, $38269,153183$.

383 39. Yin, Z.; Peng, Z.; Wang, Z.; Meng, Q., The oncogenic role of REG $\gamma$ is exerted by activating 384 the Wnt/ $\beta$-catenin signaling pathway in osteosarcoma. Am J Trans/ Res 2020, 12 (2), 563-573.

385 40. Chen, X.; Zhao, W.; Fan, W., Long non-coding RNA GHET1 promotes osteosarcoma 386 development and progression via Wnt/ $\beta$-catenin signaling pathway. Oncol Rep 2020, 44 (1), 349387359.

388

389

390

391

FIGURE 1. Result of bioinformatics analysis. (A) Protein-protein interactions (PPI) involving

392 the 28 differentially expressed genes (DEGs) were identified using the STRING database. The “experiment", “database", and "coexpression" evidence channels were chosen for network construction. Clustering was performed using the MCL algorithm with inflation parameter 10.

Different colors indicate different clusters and the line thickness indicates the strength of evidence. (B-M) Expression profile of KIF4A in cancer tissues and paring normal tissues. (N-Q) Kaplan-Meier survival curves for four cancer types in regard to KIF4A expression.

FIGURE 2. Expression of KIF4A in OS cell lines. (A) KIF4A mRNA level was higher in OS 
403 FIGURE 3. KIF4A could affect OS cell viability and colony formation and migration. (A-D) 404 Expression of KIF4A in cells was detected by RT-PCR. (E\&F) CCK8 was used to detect cell 405 proliferation. (G-I) Clone formation assay was used to detect the OD value of cloned cells. $406 * \mathrm{P}<0.05$ compared with Control, \#P<0.05 compared with si-NC, \&P<0.05 compared with oe407 NC.

408

409

410

411 $412 \mathrm{NC}, \& \mathrm{P}<0.05$ compared with oe-NC.

FIGURE 4. KIF4A could affect migration of Osteosarcoma Cells. (A\&B) Transwell assay was used to test the invasion, scale bar $=100 \mu \mathrm{m}$. (C-F)Wound healing assay was utilized to detect the migration, scale bar $=100 \mu \mathrm{m} .{ }^{*} \mathrm{P}<0.05$ compared with Control, $\# \mathrm{P}<0.05$ compared with si-

413

414

FIGURE 5. KIF4A could affect induced apoptosis and cell cycle arrest of Osteosarcoma Cells.

415 (A-L) Annexin V-FITC and PI was used to evaluate apoptosis rate. (M-X) Cell cycle was

416 detected by flow cytometry. (Y-BB)The expression of apoptosis-related proteins Bax and Bcl-2

417 and caspase- 3 were determined by Western blot analysis. $* \mathrm{P}<0.05$ compared with Control, $418 \# \mathrm{P}<0.05$ compared with si-NC, \& $\mathrm{P}<0.05$ compared with oe-NC.

419

420

TABLE 1. List of full names and sample numbers for each type of cancer.

421

422 TABLE 2. Expression conditions of the top 28 DEGs in the 12 types of cancers investigated. 


\section{Figure 1}

Figure 1 Result of bioinformatics analysis.

Result of bioinformatics analysis. (A) Protein-protein interactions (PPI) involving the 28 differentially expressed genes (DEGs) were identified using the STRING database. The "experiment", "database", and "coexpression" evidence channels were chosen for network construction. Clustering was performed using the MCL algorithm with inflation parameter 10 . Different colors indicate different clusters and the line thickness indicates the strength of evidence. (B) Expression profile of KIF4A in cancer tissues and paring normal tissues. 
A

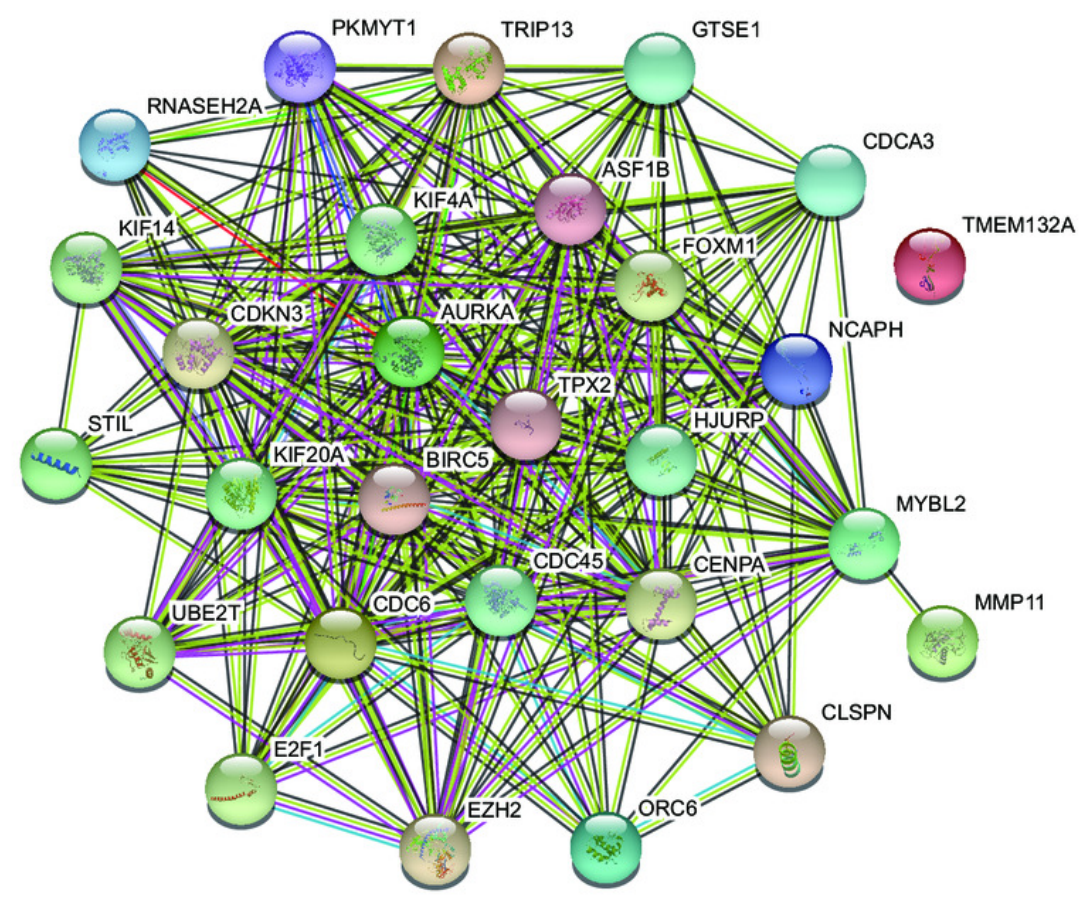

B

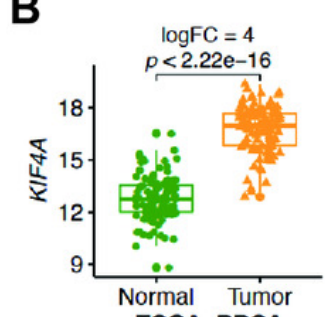

F
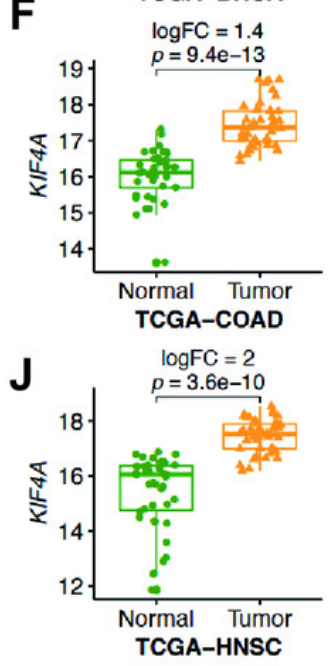

$\mathbf{N}$
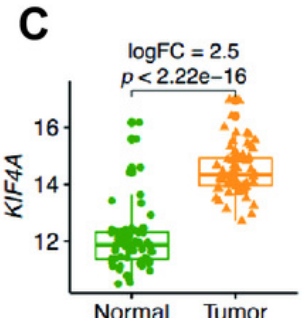

G

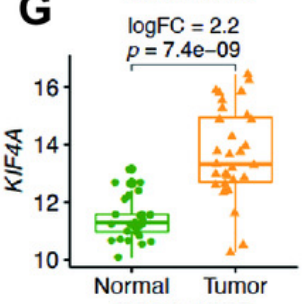

D

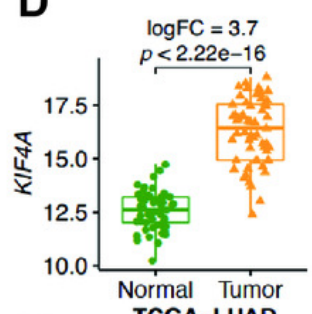

H

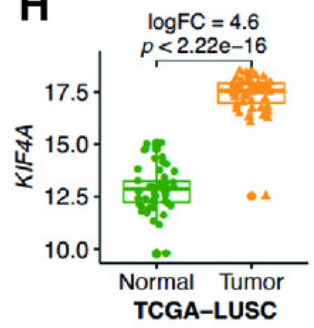

$\mathbf{E}$
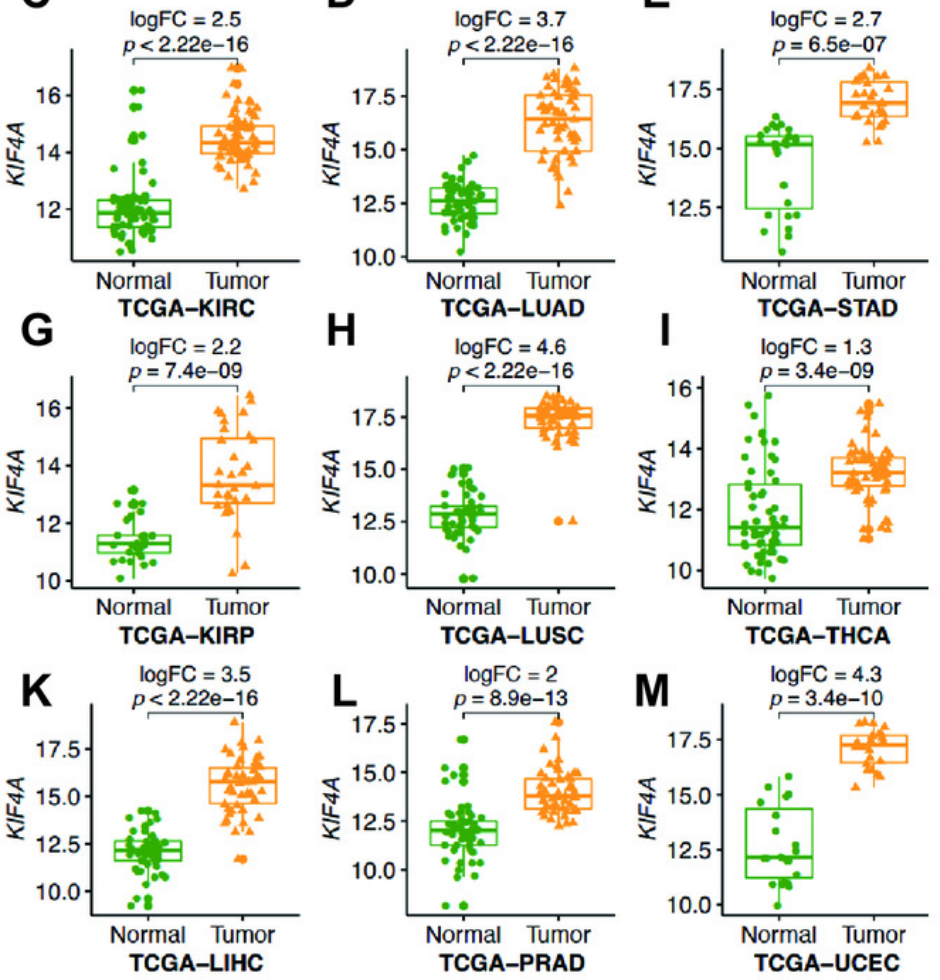

TCGA-KIRC
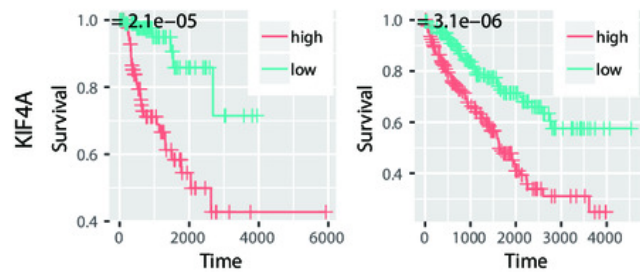

P

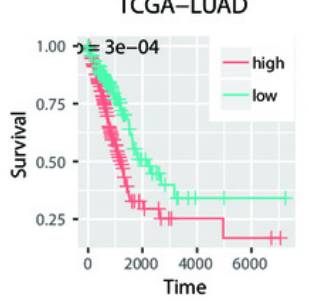

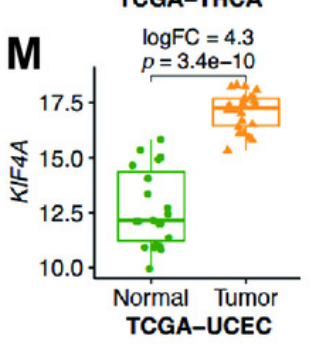

$\mathbf{Q}$

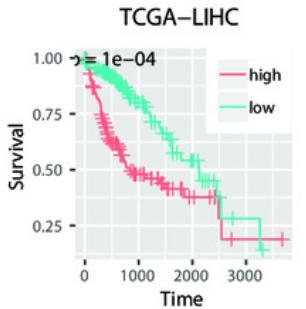


Figure 2

Figure 2 KIF4A mRNA and protein expression were down-regulated in MG63 and U2OS cells transfected with si-KIF4A.

Figure 2 KIF4A mRNA and protein expression were down-regulated in MG63 and U2OS cells transfected with si-KIF4A. (A) KIF4A mRNA level was higher in OS cells than in the normal osteoblast hFOB1.19.(B) KIF4A protein expression was significantly higher in OS cell lines than in the normal osteoblast hFOB1.19. (C) PCR assay confirmed that KIF4A mRNA expression were down-regulated in MG63 and U2OS cells transfected with si-KIF4A. ${ }^{*} p<0.05$, $* * * p<0.001$.

A

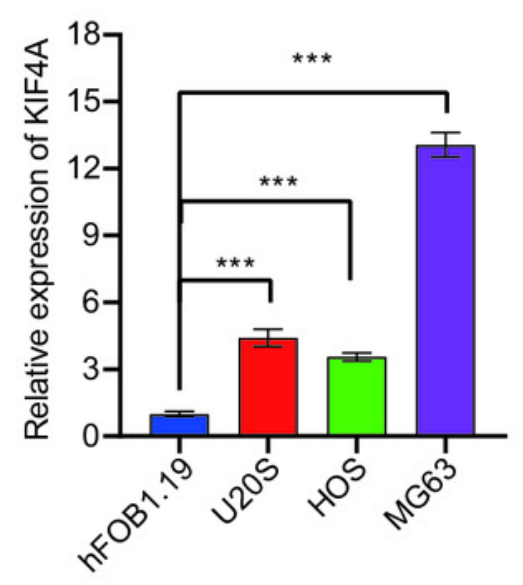

B

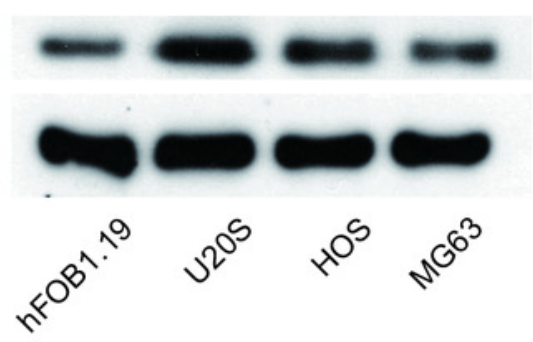

C

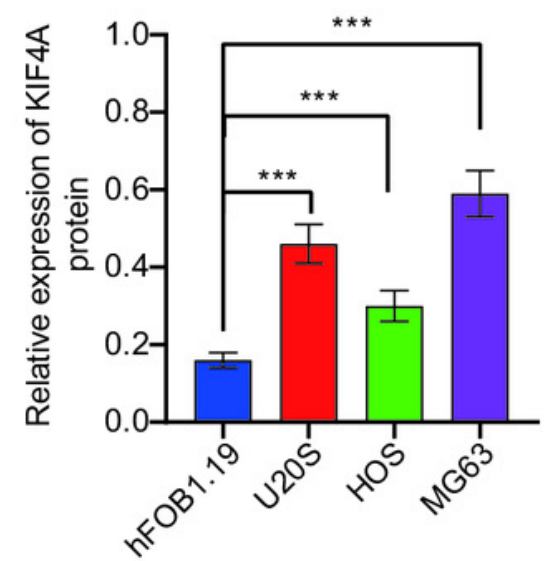




\section{Figure 3}

Figure 3 Silencing KIF4A inhibits OS cell viability and colony formation and migration.

Silencing KIF4A inhibits OS cell viability and colony formation and migration. (A) Results confirmed that in MG63 and U2OS cell lines, OS cell viability were inhibited by silencing KIF4A. (B) Colony formation results confirmed that in MG63 and U2OS cell lines, OS cell colony formation were inhibited by silencing KIF4A. (C) Transwell assay analysis results indicated that in MG63 and U2OS cell lines, OS cell invasion were inhibited by silencing KIF4A. Magnification $\times 100$, scale bar $=100 \mu \mathrm{m}$. Representative images were shown. Error bar $=$ mean \pm SD of at triplicate experiments. ${ }^{* * *} p<0.001$. 

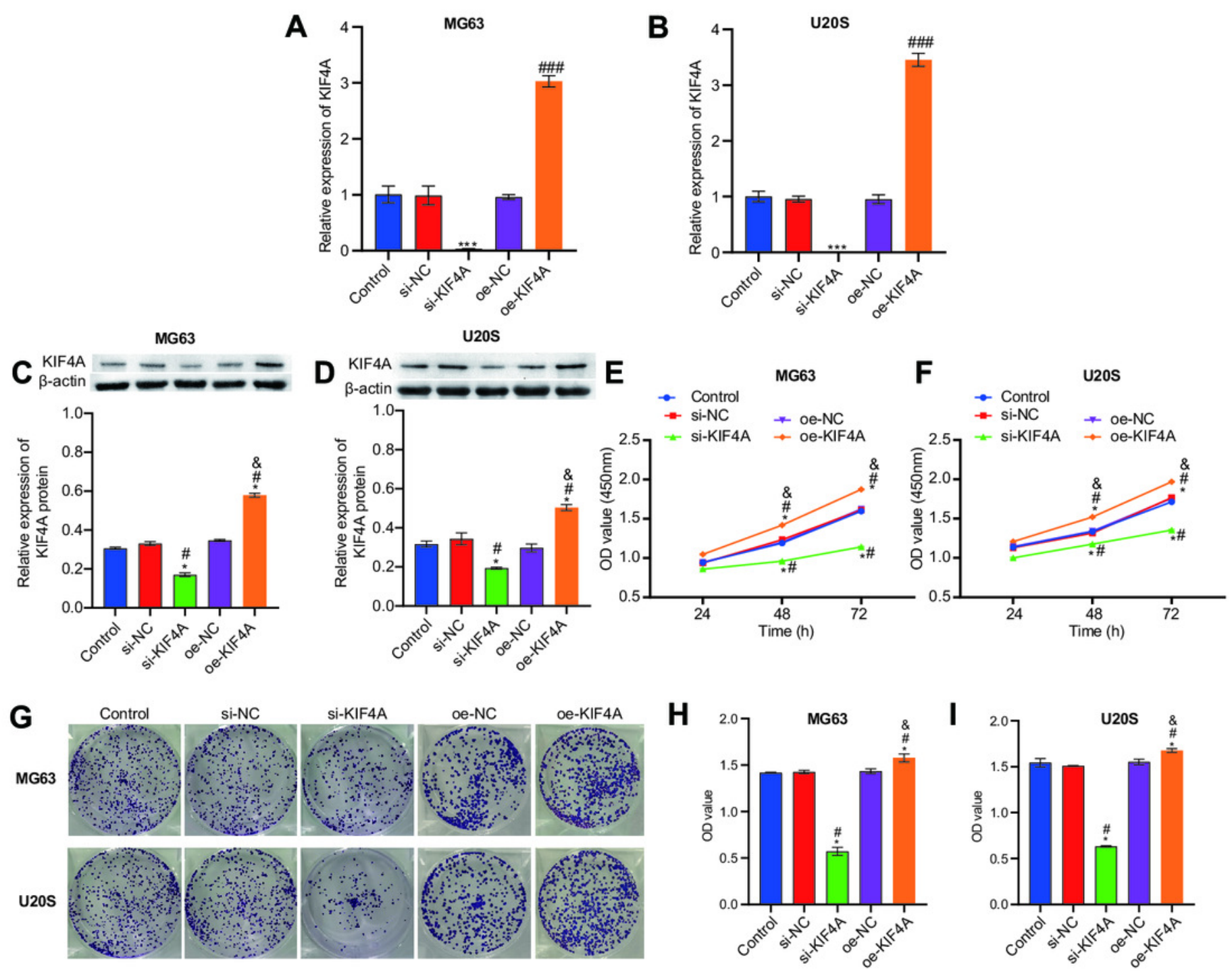


\section{Figure 4}

Figure 4 Silencing KIF4A inhibited migration of Osteosarcoma Cells.

Silencing KIF4A inhibited migration of Osteosarcoma Cells. (A and B) Wound healing assay results indicated that in MG63 and U2OS cell lines, OS cell migration were inhibited by silencing KIF4A. Magnification $\times 100$, scale bar $=100 \mu \mathrm{m}$. Representative images were shown. Magnification $\times 100$, scale bar $=100 \mu \mathrm{m}$. Error bar $=$ mean $\pm S D$ of at triplicate experiments. ${ }^{*} p<0.05, * * p<0.001$. 

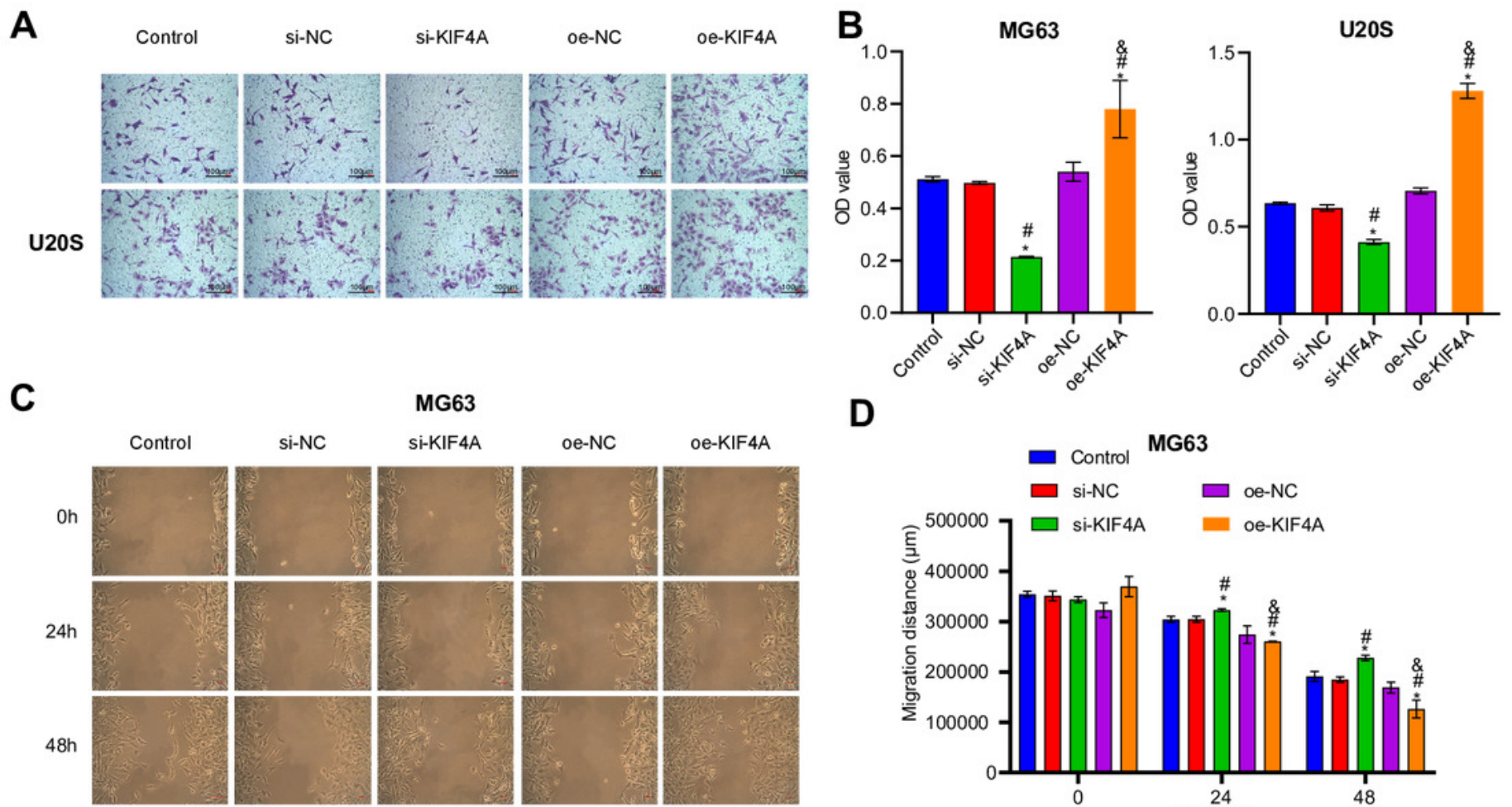

MG63

D
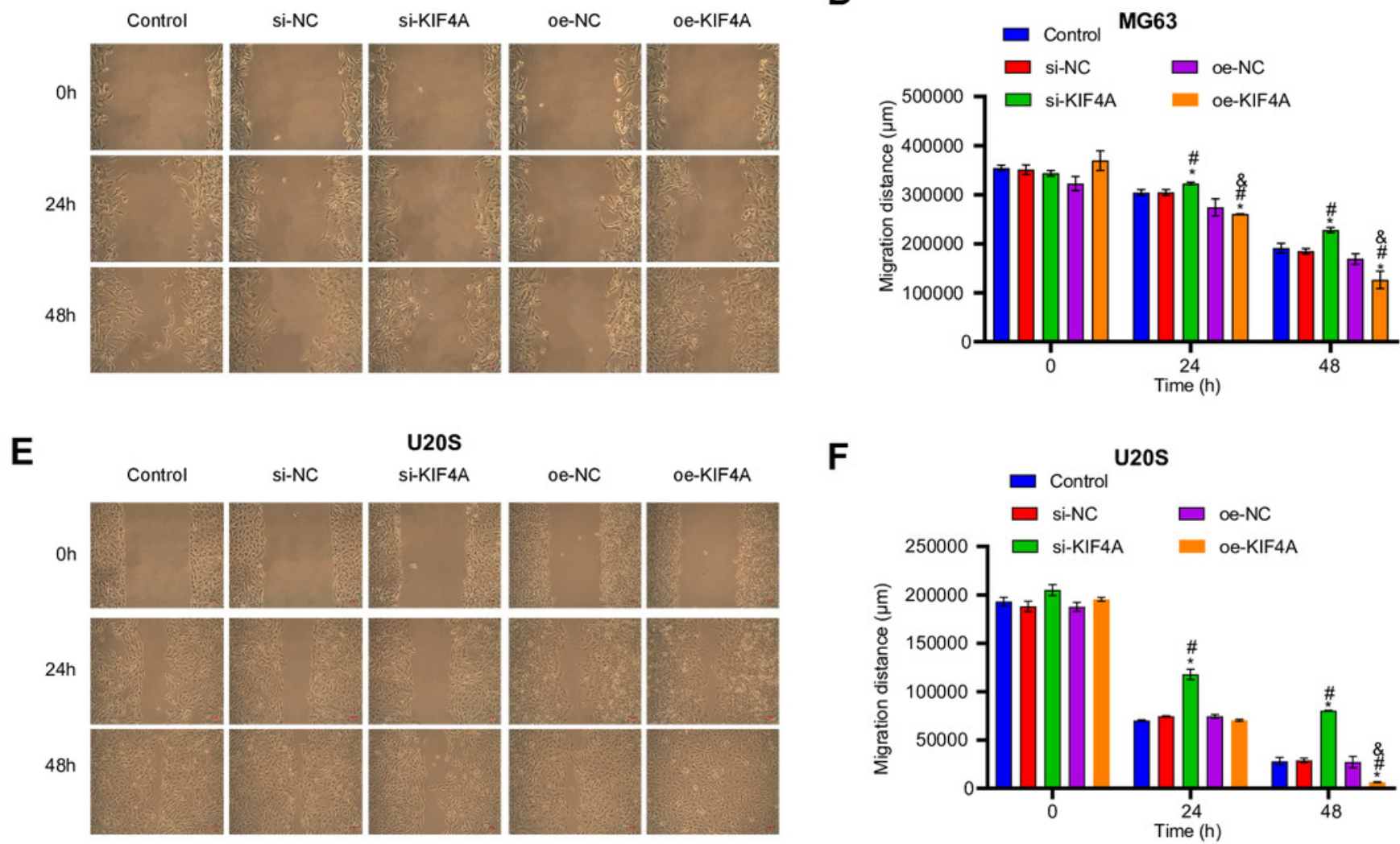

F

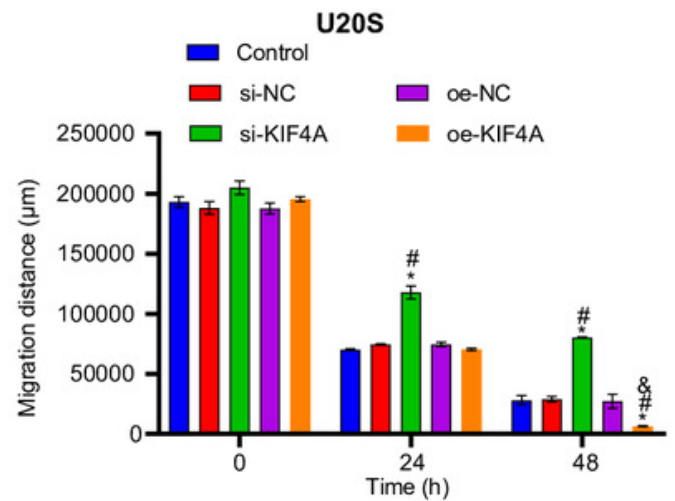




\section{Figure 5}

Figure 5 Silencing KIF4A induced apoptosis and cell cycle arrest of Osteosarcoma Cells.

Silencing KIF4A induced apoptosis and cell cycle arrest of Osteosarcoma Cells. (A) Silencing of KIF4A induced apoptosis including early apoptosis and late apoptosis. early apoptotic cells in the lower right quadrant (LR); late apoptotic cells in the upper right upper quadrant(UR). (B) Flow cytometry results showed that silencing of KIF4A induced G1-stage cell cycle arrest. Representative images were shown. Error bar $=$ mean $\pm S D$ of at triplicate experiments. (C)The expression of apoptosis-related proteins Bax and Bcl-2 and cleaved caspase-3(CC3) were determined by Western blot analysis. ${ }^{* *} p<0.01,{ }^{* * *} p<0.001$. 


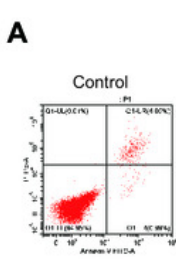

B

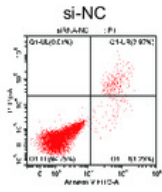

G

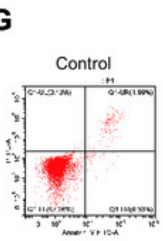

H
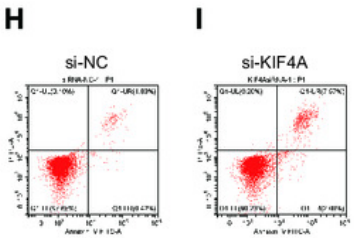

U20S
D

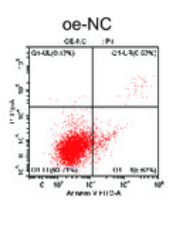

J

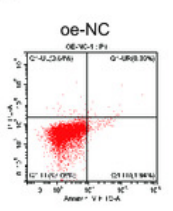

K

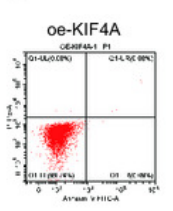

E

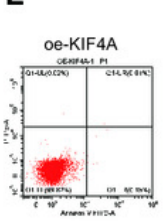

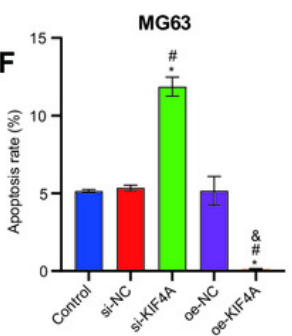

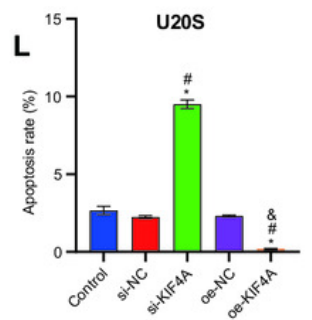

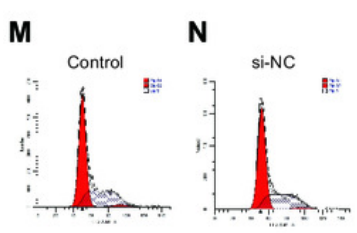
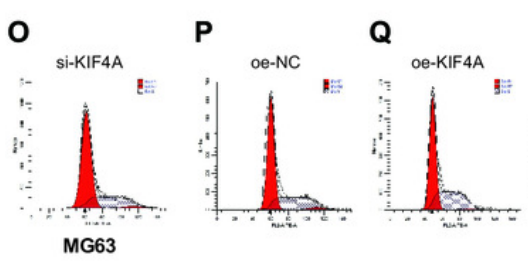

$\mathbf{R}=\begin{gathered}\text { Control } \\ \text { si-NC } \\ \text { si-KIF4A }\end{gathered}$
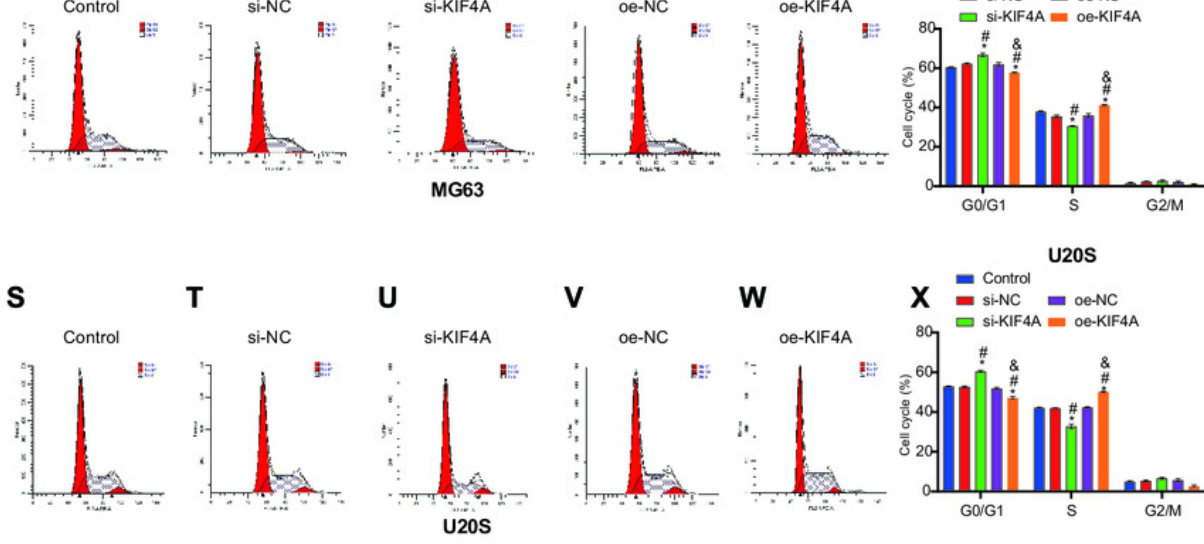

$\mathrm{X}=$ Control $^{\text {U20S }}$

$X={ }^{\text {Control }}=$ oe-NC
${ }_{80}=$ si-KIF $4 \mathrm{~A}=0 \mathrm{e}-\mathrm{KIF} 4 \mathrm{~A}$
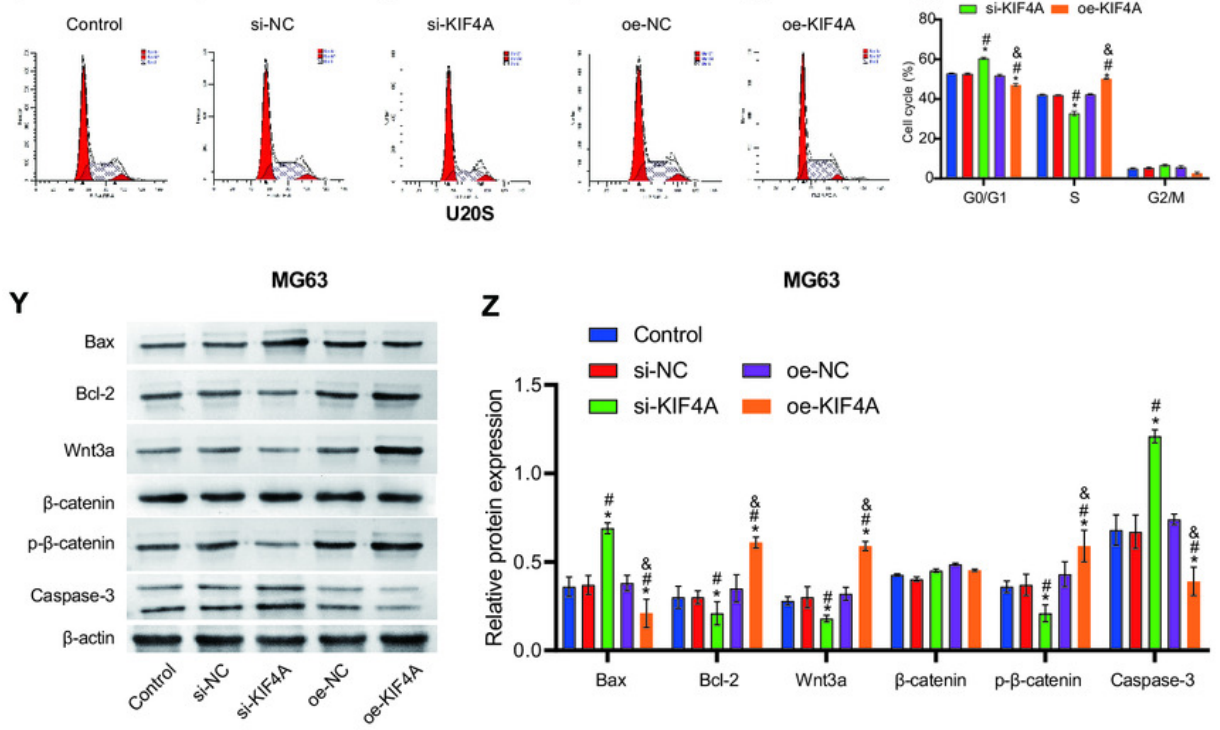

Z MG63

z
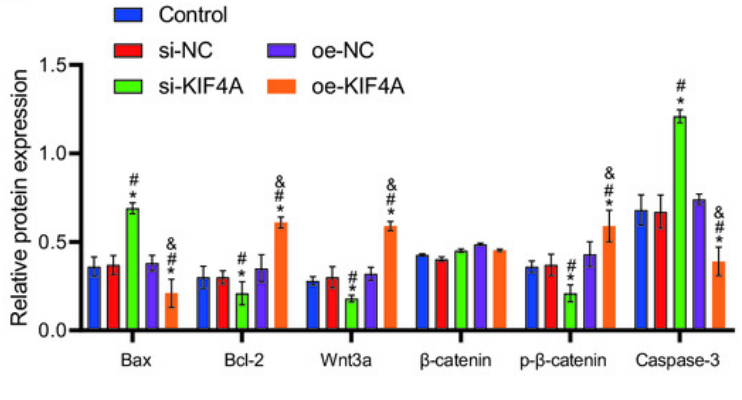

AA

U20S

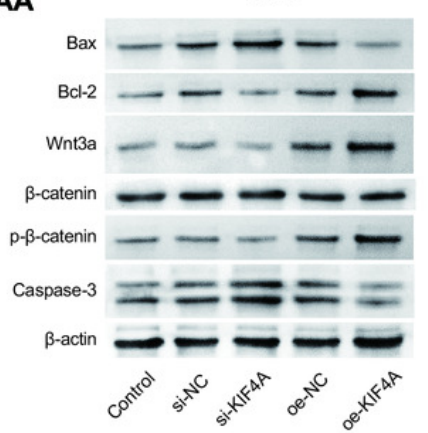

BB

U20S

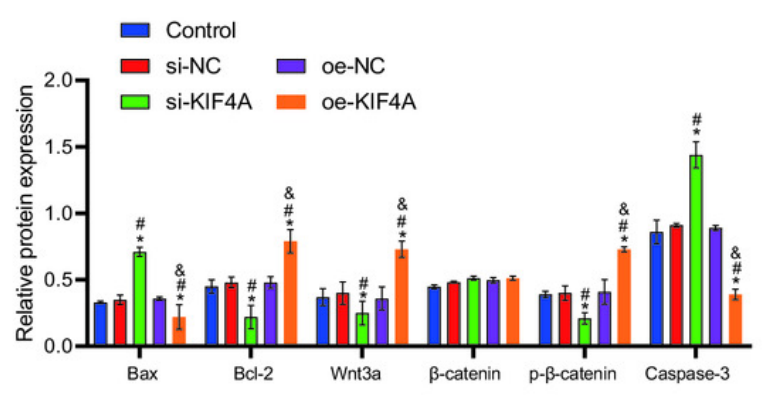




\section{Table $\mathbf{1}$ (on next page)}

Table 1 List of full names and sample numbers for each type of cancer.

List of full names and sample numbers for each type of cancer. 
1 Table 1 Full names and sample numbers for each type of cancer.

\begin{tabular}{cll}
\hline Abbr. & Cancer Type & N of Samples \\
\hline TCGA-BRCA & Breast Invasive Carcinoma & 112 \\
TCGA-COAD & Colon Adenocarcinoma & 41 \\
TCGA-HNSC & Head and Neck Squamous Cell Carcinoma & 43 \\
TCGA-KIRC & Kidney Renal Clear Cell Carcinoma & 72 \\
TCGA-KIRP & Kidney Renal Papillary Cell Carcinoma & 31 \\
TCGA-LIHC & Liver Hepatocellular Carcinoma & 50 \\
TCGA-LUAD & Lung Adenocarcinoma & 57 \\
TCGA-LUSC & Lung Squamous Cell Carcinoma & 49 \\
TCGA-PRAD & Prostate Adenocarcinoma & 52 \\
TCGA-STAD & Stomach Adenocarcinoma & 27 \\
TCGA-THCA & Thyroid Carcinoma & 58 \\
TCGA-UCEC & Uterine Corpus Endometrial Carcinoma & 23 \\
& & \\
\hline
\end{tabular}


Table 2 (on next page)

Table 2 Expression conditions of the top 28 DEGs in the 12 types of cancers investigated

Expression conditions of the top 28 DEGs in the 12 types of cancers investigated 
Table 2 Expression of the top 28 DEGs in the 12 types of cancers investigated.

\begin{tabular}{|c|c|c|c|c|c|c|c|c|c|c|c|c|c|}
\hline & BRCA & COAD & HNSC & KIRC & KIRP & LIHC & LUAD & LUSC & PRAD & STAD & THCA & UCEC & $\mathbf{N}$ \\
\hline KIF4A & + & + & + & + & + & + & + & + & + & N.S. & + & + & 11 \\
\hline STIL & + & + & + & + & + & + & + & + & + & + & N.S. & + & 11 \\
\hline TRIP13 & + & + & + & + & + & + & + & + & + & + & N.S. & N.S. & 10 \\
\hline GTSE1 & + & + & + & + & + & + & + & + & + & N.S. & N.S. & + & 10 \\
\hline UBE2T & + & + & + & + & + & + & + & + & N.S. & N.S. & + & + & 10 \\
\hline TPX2 & + & + & + & + & + & + & + & + & + & N.S. & N.S. & + & 10 \\
\hline BIRC5 & + & + & + & + & + & + & + & + & + & N.S. & N.S. & + & 10 \\
\hline ORC6 & + & + & + & + & + & + & + & + & N.S. & N.S. & + & + & 10 \\
\hline CLSPN & + & N.S. & + & + & + & + & + & + & N.S. & + & + & + & 10 \\
\hline CDC45 & + & + & + & + & + & + & + & + & N.S. & N.S. & + & + & 10 \\
\hline MYBL2 & + & + & + & + & + & + & + & + & + & N.S. & N.S. & + & 10 \\
\hline $\mathrm{E} 2 \mathrm{~F} 1$ & + & + & + & + & + & + & N.S. & + & N.S. & + & + & + & 10 \\
\hline RNASEH2A & + & + & + & + & + & + & + & + & N.S. & N.S. & + & + & 10 \\
\hline ASF1B & + & + & N.S. & + & + & + & + & + & + & N.S. & + & + & 10 \\
\hline EZH2 & + & + & N.S. & + & + & + & + & + & + & N.S. & + & + & 10 \\
\hline FOXM1 & + & + & + & + & + & + & + & + & + & N.S. & N.S. & + & 10 \\
\hline CDCA3 & + & + & + & + & + & + & + & + & + & N.S. & N.S. & + & 10 \\
\hline KIF20A & + & + & N.S. & + & + & + & + & + & + & N.S. & + & + & 10 \\
\hline CENPA & + & + & + & + & + & + & + & + & + & N.S. & N.S. & + & 10 \\
\hline
\end{tabular}




\begin{tabular}{|c|c|c|c|c|c|c|c|c|c|c|c|c|c|}
\hline NCAPH & + & + & + & + & + & + & + & + & + & N.S. & N.S. & + & 10 \\
\hline HJURP & + & + & + & + & + & + & + & + & + & N.S. & N.S. & + & 10 \\
\hline PKMYT1 & + & + & + & + & + & + & + & + & N.S. & N.S. & + & + & 10 \\
\hline
\end{tabular}

2 ("+": specific gene is overexpressed in that cancer type compared to normal tissue. "N.S.": not significant.) 